\title{
Fluvastatin decreasing interleukin-8 production may be used to reduce cardiovascular risk in patients with Behcet's disease
}

\author{
Yinfang $\mathbf{W}^{1,2,3}$ and Xiaodong $\mathrm{S}^{1,2,3 *}$ \\ ${ }^{1}$ Department of Hepatobiliary and Pancreatic Surgery, Zhejiang Provincial People's Hospital, People’s Hospital of Hangzhou Medical College, Hangzhou 310014, \\ Zhejiang Province, PR China \\ ${ }^{2}$ Key Laboratory of Tumor Molecular Diagnosis and Individualized Medicine of Zhejiang Province, Hangzhou 310014, Zhejiang Province, PR China \\ ${ }^{3}$ The Second Clinical Medical College, Zhejiang Chinese Medical University, Hangzhou 310000, Zhejiang Province, PR China
}

Behcet's disease (BD) frequently occurs in our daily clinical work. $\mathrm{BD}$ patients usually need intensive care in the late-stage of the disease because of frequently occurred cardiovascular events [1-3]. However, potential medical interventions to patients with $\mathrm{BD}$ still remain unclear. Here, we speculate that fluvastatin decreasing interleukin-8 (IL-8) production could be used to reduce the cardiovascular risk in BD patients.

$\mathrm{BD}$ is characterized by a multi-systemic inflammatory disorder. Previous studies showed serum IL-8 levels were significantly elevated in BD patients [4]. Furthermore, there is sufficient evidence to support that IL- 8 was involved in the establishment and preservation of the vessel wall inflammation within numerous cardiovascular disease, such as atherosclerosis and myocardial infarction [5], showing a novel intervention target for BD. Importantly, fluvastatin, a HMG CoA reductase inhibitor, has been firmly identified to decrease IL-8 production in whole blood ${ }^{6}$ and human vascular smooth muscle cells $[6,7]$, suggesting its potential intervention role in cardiovascular risk in $\mathrm{BD}$ patients. Moreover, in addition to the possible way through regulation of IL-8, fluvastatin has been widely confirmed to achieve a remarkable therapeutic effect on cardiovascular disease by modulating lipid metabolism.

In conclusion, fluvastatin may reverse the up-regulation of serum IL-8 levels in $\mathrm{BD}$. If so, reasonable application of fluvastatin as a conventional medication presents a potential therapeutic approach for treating IL-8induced cardiovascular morbidity and mortality in BD patients.

\section{Conflicts of interest}

There are no conflicts of interest associated with this manuscript.

\section{References}

1. Wu XY, Wei JP, Zhao XY, Wang Y, Wu HH, et al. (2015) Spontaneous Intra-Abdominal Hemorrhage Due to Rupture of Jejunal Artery Aneurysm in Behcet Disease: Case Report and Literature Review. Medicine (Baltimore) 94: e1979. [Crossref]

2. Yavne $\mathrm{Y}$, Tiosano $\mathrm{S}$, Watad A, Comaneshter D, Cohen AD, et al. (2017) Investigating the link between ischemic heart disease and Behcet's disease: A cross-sectional analysis. Int J Cardiol 241: 41-45. [Crossref]

3. Rico JV, Pedrajas FG, González IC, Iglesias RJ (2011) Urgent endovascular treatment of a ruptured tibioperoneal pseudoaneurysm in Behçet's disease. Ann Vasc Surg 25: 385. e11-385. e14.

4. Kartal Durmazlar SP, Ulkar GB, Eskioglu F, Tatlican S, Mert A, et al. (2009) Significance of serum interleukin-8 levels in patients with Behcet's disease: high levels may indicate vascular involvement. Int J Dermatol 48: 259-264.

5. Apostolakis S, Vogiatzi K, Amanatidou V, Spandidos DA (2009) Interleukin 8 and cardiovascular disease. Cardiovasc Res 84: 353-360. [Crossref]

6. Jouneau S, Bonizec M, Belleguic C, Desrues B, Brinchault G, et al. (2011) Antiinflammatory effect of fluvastatin on IL-8 production induced by Pseudomonas aeruginosa and Aspergillus fumigatus antigens in cystic fibrosis. PLoS ONE 6: e22655.

7. Ito T, Ikeda U, Yamamoto K, Shimada K (2002) Regulation of interleukin-8 expression by HMG-CoA reductase inhibitors in human vascular smooth muscle cells Atherosclerosis 165: 51-55.
Copyright: (C2017 Yinfang W. This is an open-access article distributed under the terms of the Creative Commons Attribution License, which permits unrestricted use, distribution, and reproduction in any medium, provided the original author and source are credited.
Correspondence to: Xiaodong Sun, Department of Hepatobiliary and Pancreatic Surgery, Zhejiang Provincial People’s Hospital, No. 158 Shangtang Road, Hangzhou 310000, Zhejiang Province, PR China, Tel: 0086-571-85893311; Fax: 0086-571-85131448; E-mail: sunxiaodong@hmc.edu.cn

Key words: Behcet's disease, Fluvastatin, Interleukin-8, Cardiovascular risk

Received: October 20, 2017; Accepted: November 13, 2017; Published: November 17,2017 